\title{
Cross-Nation Comparison of Oral Cancer in the Eastern Mediterranean Region: an Ecological Overview
}

\author{
Amit Chattopadhyay ${ }^{1,2}$
}

Published online: 24 July 2015

(C) Springer International Publishing AG 2015

\begin{abstract}
Eastern Mediterranean (EM) region countries include countries from the Mediterranean region and North Africa representing regions with wide variations in their politics, economy, peaceful status, and healthcare infrastructure. Commonly known lip and oral cancer risk factors such as consumption of tobacco and alcohol are widely prevalent in the region. Globocan data suggests that age-standardized incidence rates and age-adjusted mortality rates are higher in the region compared to world averages whereas 1-, 2-, and 3-year prevalence proportions are lower. These statistical profiles are generally similar for men and women. Within the region, in general, incidence, mortality, and prevalence is greater in men than women. However, there are important differences in overall incidence, prevalence, and mortality; differences between genders in these statistics which vary between countries. This manuscript describes and compares oral cancer statistics of the countries in the EM region.
\end{abstract}

This article is part of the Topical Collection on Dental Public Health

Publication Statement This work described has not been published previously, is not under consideration for publication elsewhere, and is approved by all authors.

Amit Chattopadhyay

Amit.Chattopadhyay@dhcc.ae

1 Department of Oral Medicine, Case Western Reserve University School of Dental Medicine, Cleveland, OH, USA

2 Mohammed Bin Rashid University of Medicine and Health Sciences, Mohammed Bin Rashid Academic Medical Center (Bldg 14), Dubai Healthcare City, Dubai, United Arab Emirates
Keywords Oral cancer · Eastern Mediterranean · Incidence · Prevalence $\cdot$ Mortality $\cdot$ Globocan

\section{Introduction}

Eastern Mediterranean (EM) region countries include countries from the Mediterranean region and North Africa. The World Health Organization (WHO) has a regional office for the area (EMRO) providing services to: Afghanistan, Bahrain, Djibouti, Egypt, Islamic Republic of Iran, Iraq, Jordan, Kuwait, Lebanon, Libya, Morocco, Oman, Pakistan, Palestine, Qatar, Saudi Arabia, Somalia, Sudan, Syrian Arab Republic, Tunisia, United Arab Emirates, and Yemen [1]. Though there is a fabric of religious and cultural commonality in the region, the countries vary widely in terms of economy, industry, political structure, political stability, per-capita income, human rights, and importantly, evolution and development of health systems resulting in wide variations in their health indicators. Currently, political upheaval, wars, and civic strife characterize several countries in the region.

Lip and oral cancer risk factors such as consumption of tobacco and alcohol are widely prevalent in the EM region. Intensity of sunlight (and associated exposure to UV light) in the region is also a widely prevalent risk factor for lip cancer. All over the world, late recognition of oral cancer is an important factor for its poor prognosis [2]. Awareness of oral cancer of understanding of the risks due to the common habits such as smoking is expected to be low in the region.

The Globocan project is run by The International Agency for Research on Cancer (IARC) which is part of the WHO. This project provides contemporary 
estimates of the incidence of mortality and prevalence from major types of cancer, at national level, for 184 countries in the world [3]. At this time, the GLOBOCAN estimates are available from IARC for 2012 based on the most recent data available with them. The data analyzed below by the author were extracted in aggregate format using Globocan 2012 data source and analytical tools for lip and oral cancer henceforth referred to as "oral cancer." Some data extracted were re-formatted and analyzed separately in commonly available statistical and office automation tools.

Cancer is the fourth leading cause of death in the EM region and its incidence is increasing rapidly [4•]. Oral cancer was reported to be one of the top five prevalent cancers in Sudan, Pakistan, and Afghanistan in the EM region in 2002 although incidence and mortality statistics were not published. To the best of our knowledge, this is the first study that compares these basic statistics for oral cancer in this region.

\section{Incidence}

Though the overall average crude incidence rate of lip and oral cavity of the EM region at 3.3 new cases per 100,000 persons at risk is lower than the world average of 4.3 new cases per 100,000 persons at risk, the agestandardized rates were higher in EM region $(4.6 / 100$, 000) compared to the world average $(4.0 / 100,000)$. However, there is a wide range of rates within the region, with the lowest in Kuwait (crude: 0.9/100,000; age standardized; 1.5/100,000) and highest in Pakistan (crude: 7.1/100,000; age standardized; 9.8/100,000) (Table 1). Whereas crude rates between countries may not be directly comparable due to different population age distributions, they provide an idea about national oral cancer burden on which health policies can be realistically based. However, upon age standardization (on world standard population, calculated using 10 age groups) [5], it is seen that the average agestandardized rate (ASR), of the EM region (4.6/100, $000)$ is greater than that of the world average (4.0/ $100,000)$ with a wide range across countries (Table 1).

Lifetime cumulative risk for incidence at birth is defined as the "number of new born children (out of 100) who would be expected to develop a particular cancer before the age of 75 if they had the rates of cancer observed in the period in the absence of competing causes" [5]. As seen in Table 1, the average lifetime cumulative risk for oral cancer in EM region $(0.52)$ is greater than the world average $(0.45)$ with the greatest risk being in Pakistan (7.7) and lowest being reported in Jordan and Libya ( 0.15 each). The only other country where the risk was greater than EMRO average was Afghanistan
(0.71). In all other countries, the risk was below world average though Somalia came close to world average (0.42). Data quality from Afghanistan is poor, and incidence data is not directly available. The rates therefore reflect those of neighboring regions with similar socio-demographic profile. Data issues are discussed in a different section at the end of the report.

The general patterns for incidence rates and risk among men and women were similar to the overall pattern described above with higher rates and risks in Pakistan and Afghanistan compared to the rest of the region, being substantially greater among men than women except in Yemen where the reverse was reported. The incidence rates and differences in risks between men and women were substantially narrowed in $\mathrm{Ku}$ wait, Libya, Qatar, and Saudi Arabia (Table 1).

\section{Prevalence}

Whereas Table 2 demonstrates 1-, 3-, and 5-year prevalence proportions (per 100,000 persons at risk) of oral cancer, Fig. 1 depicts the 5-year prevalence of oral cancer in the EM region for men and women. Overall, the average prevalence in the EM region is lower than the world average. Similar to the pattern for incidence of oral cancer, the prevalence in Afghanistan and Pakistan were substantially above the proportions in the rest of the region. In Afghanistan, the prevalence was the same as the world average whereas Pakistan's statistics was almost double the world average. Other countries that had relatively higher prevalence in the region, even though lower than the average, were Somalia, South Sudan, Egypt, Morocco, and the state of Palestine (Table 2).

Prevalence proportion of oral cancer in the EM region increased over time as 1-year proportions were lower than 3 years, which were in turn, lower than 5 -year proportions. This implies that more persons with cancer are surviving till those time periods than dying. A clear implication from this observation for all EM region countries was that, as cancer survivorship increases over time, there will be more pressure on the countries in the EM region to provide services and facilities for people living with cancer or its consequences.

In general, the prevalence of oral cancer was lower in women than in men (Table 2) except in United Arab Emirates where the proportions were similar between genders; and in Saudi Arabia and Yemen where the prevalence in women was substantially higher than in men for the 1-, 3-, and 5-year statistics (Table 2, Fig. 1). Focused studies may be able to unearth the reasons for higher prevalence among women (perhaps better survival compared to men for a variety of possible reasons including easier accessibility of health system or earlier presentation). 
Table 1 Estimated incidence: lip, oral cavity for EM region

\begin{tabular}{|c|c|c|c|c|c|c|c|c|c|}
\hline \multirow[t]{2}{*}{ Region } & \multicolumn{3}{|c|}{ All ages, both sexes } & \multicolumn{3}{|c|}{ All ages: male } & \multicolumn{3}{|c|}{ All ages: female } \\
\hline & Crude rate & ASR & Cumulative risk & Crude rate & ASR & Cumulative risk & Crude rate & ASR & Cumulative risk \\
\hline World & 4.3 & 4.0 & 0.45 & 5.6 & 5.5 & 0.64 & 2.9 & 2.5 & 0.28 \\
\hline EM Region & 3.3 & 4.6 & 0.52 & 3.6 & 5.1 & 0.58 & 3.0 & 4.1 & 0.47 \\
\hline Afghanistan & 3.1 & 6.3 & 0.71 & 3.5 & 7.1 & 0.80 & 2.7 & 5.4 & 0.62 \\
\hline Bahrain & 1.3 & 2.2 & 0.26 & 1.6 & 3.2 & 0.34 & 0.8 & 1.2 & 0.15 \\
\hline Djibouti & 1.6 & 2.7 & 0.32 & 1.7 & 3.2 & 0.37 & 1.5 & 2.3 & 0.27 \\
\hline Egypt & 2.0 & 2.4 & 0.27 & 2.3 & 2.9 & 0.33 & 1.7 & 1.9 & 0.21 \\
\hline Iran, Islamic Republic of & 1.8 & 2.0 & 0.22 & 2.0 & 2.2 & 0.24 & 1.7 & 1.8 & 0.20 \\
\hline Iraq & 1.2 & 2.3 & 0.26 & 1.3 & 3.0 & 0.36 & 1.1 & 1.7 & 0.19 \\
\hline Jordan & 1.1 & 1.7 & 0.15 & 1.4 & 2.2 & 0.19 & 0.9 & 1.2 & 0.11 \\
\hline Kuwait & 0.9 & 1.5 & 0.16 & 0.9 & 1.5 & 0.17 & 0.8 & 1.3 & 0.14 \\
\hline Lebanon & 2.1 & 2.0 & 0.22 & 2.6 & 2.6 & 0.30 & 1.7 & 1.5 & 0.16 \\
\hline Libya & 1.0 & 1.3 & 0.15 & 0.9 & 1.3 & 0.15 & 1.0 & 1.3 & 0.14 \\
\hline Morocco & 2.2 & 2.5 & 0.30 & 2.6 & 3.0 & 0.38 & 1.8 & 1.9 & 0.22 \\
\hline Oman & 1.2 & 1.8 & 0.21 & 1.3 & 1.9 & 0.23 & 1.0 & 1.7 & 0.18 \\
\hline Pakistan & 7.1 & 9.8 & 1.13 & 7.7 & 10.5 & 1.18 & 6.4 & 9.1 & 1.07 \\
\hline Qatar & 1.2 & 2.1 & 0.21 & 1.4 & 2.0 & 0.25 & 0.6 & 1.9 & 0.10 \\
\hline Saudi Arabia & 1.2 & 2.0 & 0.24 & 1.2 & 2.0 & 0.24 & 1.3 & 2.1 & 0.24 \\
\hline Somalia & 1.9 & 3.5 & 0.42 & 1.9 & 3.7 & 0.43 & 1.9 & 3.4 & 0.41 \\
\hline South Sudan & 1.8 & 3.2 & 0.38 & 2.1 & 4.0 & 0.46 & 1.5 & 2.5 & 0.31 \\
\hline State of Palestine & 2.1 & 3.8 & 0.41 & 2.0 & 3.4 & 0.35 & 2.2 & 4.1 & 0.47 \\
\hline Sudan & 1.6 & 3.0 & 0.34 & 2.0 & 3.7 & 0.42 & 1.3 & 2.3 & 0.26 \\
\hline Syrian Arab Republic & 1.4 & 2.0 & 0.22 & 1.7 & 2.7 & 0.29 & 1.1 & 1.5 & 0.15 \\
\hline Tunisia & 2.2 & 2.1 & 0.23 & 2.7 & 2.7 & 0.30 & 1.7 & 1.5 & 0.16 \\
\hline United Arab Emirates & 1.0 & 2.1 & 0.27 & 1.1 & 2.4 & 0.31 & 0.8 & 1.5 & 0.16 \\
\hline Yemen & 1.1 & 2.2 & 0.24 & 1.0 & 2.0 & 0.22 & 1.2 & 2.3 & 0.25 \\
\hline
\end{tabular}

Rates are per 100,000 populations at risk

EM region Eastern Mediterranean, ASR age-standardized rate (against world standard population)

Data source: IARC, Globocan 2012

\section{Mortality}

As seen in Table 3, the overall average crude mortality rate in the EM region $(1.8 / 100,000)$ is lower than the world average of $2.1 / 100,000$. However, the agestandardized mortality rate in EM region $(2.5 / 100,000)$ was higher than the world average $(1.9 / 100,000)$. This pattern was also noted in the incidence statistics. Highest overall mortality rate was seen in Pakistan $(5.9 / 100,000)$ followed by Afghanistan (5.1/100,000). Unlike incidence statistics, age-adjusted mortality rates of Afghanistan were very close to Pakistan's rates even though their crude mortality rates were substantially apart (Pakistan 4.0/100,000; Afghanistan 2.3/100,000). Population demographic dynamics in war-torn Afghanistan probably play a large role in the differential mortality statistics compared to Pakistan as noted above.
As is the pattern seen till now in all oral cancerrelated statistics, the cumulative risk of dying from oral cancer at birth (newborn children who would be expected to die from oral cancer before the age of 75 if they had the rates of cancer observed in the period in the absence of competing causes) in Pakistan (0.7) is the highest in the EM region followed by Afghanistan (0.6). Most other countries in the region have substantially lower cumulative lifetime risk of dying from oral cancer with several countries having cumulative mortality risk from oral cancer at birth between 0.4 and 0.7 (Table 3).

Patterns noted earlier were also seen in oral cancerrelated mortality statistics for men and women: overall mortality rates for the region and most countries were higher for men than women with few exceptions. Agestandardized mortality rates for oral cancer were very 
Table 2 Estimated prevalence: lip, oral cavity for EM region

\begin{tabular}{|c|c|c|c|c|c|c|c|c|c|}
\hline \multirow[t]{2}{*}{ Region } & \multicolumn{3}{|c|}{ Adult population: both sexes } & \multicolumn{3}{|c|}{ Adult population: males } & \multicolumn{3}{|c|}{ Adult population: females } \\
\hline & $\begin{array}{l}1 \text { year } \\
N \text { (prop.) }\end{array}$ & $\begin{array}{l}3 \text { years } \\
N \text { (prop.) }\end{array}$ & $\begin{array}{l}5 \text { years } \\
N \text { (prop.) }\end{array}$ & $\begin{array}{l}1 \text { year } \\
N \text { (prop.) }\end{array}$ & $\begin{array}{l}3 \text { years } \\
N \text { (prop.) }\end{array}$ & $\begin{array}{l}5 \text { years } \\
N \text { (prop.) }\end{array}$ & $\begin{array}{l}1 \text { year } \\
N \text { (prop.) }\end{array}$ & $\begin{array}{l}3 \text { years } \\
N \text { (prop.) }\end{array}$ & $\begin{array}{l}5 \text { years } \\
N \text { (prop.) }\end{array}$ \\
\hline World & $201,337(3.9)$ & $489,377(9.4)$ & $702,149(13.5)$ & $134,777(5.2)$ & $326,575(12.6)$ & $467,157(18.0)$ & $66,560(2.6)$ & $162,802(6.3)$ & $234,992(9.0)$ \\
\hline EM Region & $13,274(3.2)$ & $33,151(8.0)$ & $48,806(11.8)$ & $7397(3.5)$ & $18,510(8.7)$ & $27,236(12.9)$ & $5877(2.9)$ & $14,641(7.2)$ & $21,570(10.7)$ \\
\hline Afghanistan & $669(3.7)$ & $1659(9.2)$ & $2451(13.5)$ & $401(4.3)$ & $993(10.6)$ & $1461(15.6)$ & $268(3.1)$ & $666(7.6)$ & $990(11.4)$ \\
\hline Bahrain & $8(0.7)$ & $20(1.8)$ & $30(2.8)$ & $8(1.1)$ & $20(2.8)$ & $30(4.2)$ & $0(0.0)$ & $0(0.0)$ & $0(0.0)$ \\
\hline Djibouti & $9(1.5)$ & $23(3.8)$ & $35(5.8)$ & $4(1.3)$ & $12(4.0)$ & $19(6.4)$ & $5(1.7)$ & $11(3.7)$ & $16(5.3)$ \\
\hline Egypt & $1063(1.8)$ & $2647(4.6)$ & $3876(6.7)$ & $622(2.2)$ & $1538(5.3)$ & $2239(7.8)$ & $441(1.5)$ & $1109(3.8)$ & $1637(5.6)$ \\
\hline Iran, Islamic Republic of & $827(1.4)$ & $2057(3.5)$ & $3024(5.2)$ & 459 (1.6) & $1138(3.8)$ & $1673(5.7)$ & $368(1.3)$ & $919(3.2)$ & $1351(4.7)$ \\
\hline Iraq & $246(1.3)$ & $621(3.2)$ & 917 (4.7) & $141(1.5)$ & 354 (3.7) & $521(5.5)$ & $105(1.1)$ & $267(2.7)$ & $396(4.0)$ \\
\hline Jordan & $47(1.1)$ & $116(2.8)$ & $169(4.1)$ & $29(1.4)$ & $71(3.3)$ & $101(4.7)$ & $18(0.9)$ & $45(2.2)$ & $68(3.4)$ \\
\hline Kuwait & $23(1.1)$ & $60(2.8)$ & $87(4.1)$ & $14(1.1)$ & $38(2.9)$ & $54(4.1)$ & $9(1.1)$ & $22(2.8)$ & $33(4.1)$ \\
\hline Lebanon & $54(1.6)$ & $128(3.9)$ & $186(5.7)$ & $33(2.1)$ & $77(4.9)$ & $112(7.1)$ & $21(1.2)$ & $51(3.0)$ & $74(4.4)$ \\
\hline Libya & $41(0.9)$ & $100(2.2)$ & $143(3.2)$ & $19(0.9)$ & $46(2.1)$ & $65(3.0)$ & $22(1.0)$ & $54(2.4)$ & $78(3.4)$ \\
\hline Morocco & $469(2.0)$ & $1162(4.9)$ & $1703(7.2)$ & $270(2.4)$ & $674(5.9)$ & 995 (8.7) & 199 (1.6) & $488(4.0)$ & $708(5.8)$ \\
\hline Oman & $21(1.0)$ & $53(2.5)$ & $76(3.6)$ & $14(1.1)$ & $36(2.8)$ & $52(4.0)$ & $7(0.9)$ & $17(2.1)$ & $24(3.0)$ \\
\hline Pakistan & $8279(7.0)$ & $20,779(17.6)$ & $30,647(26.0)$ & $4520(7.6)$ & $11,360(19.0)$ & $16,781(28.1)$ & $3759(6.5)$ & 9419 (16.2) & $13,866(23$ \\
\hline Qatar & $15(0.9)$ & $43(2.6)$ & $64(3.9)$ & $15(1.1)$ & $43(3.3)$ & $64(4.8)$ & $0(0.0)$ & $0(0.0)$ & $0(0.0)$ \\
\hline Saudi Arabia & $225(1.1)$ & $559(2.8)$ & $822(4.1)$ & $122(1.1)$ & $307(2.7)$ & 449 (3.9) & $103(1.2)$ & $252(2.9)$ & $373(4.3)$ \\
\hline Somalia & $120(2.2)$ & $299(5.5)$ & $442(8.2)$ & $57(2.2)$ & $144(5.4)$ & $212(8.0)$ & $63(2.3)$ & $155(5.6)$ & $230(8.4)$ \\
\hline South Sudan & $123(2.0)$ & $303(4.8)$ & $442(7.1)$ & $74(2.4)$ & $181(5.8)$ & $263(8.5)$ & $49(1.6)$ & $122(3.9)$ & $179(5.7)$ \\
\hline State of Palestine & $73(2.9)$ & $133(5.3)$ & $213(8.5)$ & $27(2.1)$ & $64(5.1)$ & $98(7.8)$ & $46(3.7)$ & $69(5.6)$ & $115(9.3)$ \\
\hline Sudan & $382(1.8)$ & $942(4.3)$ & $1372(6.3)$ & $234(2.2)$ & $574(5.3)$ & $833(7.7)$ & $148(1.4)$ & $368(3.4)$ & $539(4.9)$ \\
\hline Syrian Arab Republic & $185(1.4)$ & $471(3.5)$ & $687(5.0)$ & $112(1.6)$ & $289(4.2)$ & $418(6.1)$ & $73(1.1)$ & $182(2.7)$ & $269(4.0)$ \\
\hline Tunisia & $155(1.9)$ & $376(4.6)$ & $542(6.6)$ & $94(2.3)$ & $227(5.6)$ & $326(8.0)$ & $61(1.5)$ & 149 (3.6) & $216(5.2)$ \\
\hline United Arab Emirates & $67(1.0)$ & $178(2.6)$ & $267(4.0)$ & $48(1.0)$ & $131(2.7)$ & $194(3.9)$ & $19(1.0)$ & $47(2.6)$ & $73(4.0)$ \\
\hline Yemen & $173(1.2)$ & $422(2.9)$ & $611(4.2)$ & $80(1.1)$ & $193(2.7)$ & $276(3.9)$ & $93(1.3)$ & $229(3.2)$ & $335(4.6)$ \\
\hline
\end{tabular}

Proportions are per 100,000 population at risk

EM region Eastern Mediterranean region, $N$ Number, prop proportion

Data source: IARC, Globocan 2012

close or similar between the sexes in Iran, Libya, Saudi Arabia, and United Arab Emirates. However, agestandardized mortality rates due to oral cancer were greater in women than in men in Kuwait, Palestine, and Yemen. The cumulative risk at birth of dying from oral cancer in these three countries was also greater for women than men.

\section{Predicted Cases}

Predicting the future occurrence of cancer in term of incidence or mortality, even though fraught with uncertainty, can help planners in estimating future needs, plan for prevention, assess consequences of treatments, and allocating resources for activities to reduce and/or control the impact of cancer. The Globocan prediction tool has to be used with caution due to limitations of the data sets used for making the predictions (see "Data Limitations"). However, using year 2012 as the base year, data projections analyzed till the year 2035 indicate that in the EM region, the number of new cancer cases being diagnosed will keep increasing rapidly even if the current general conditions apply (Fig. 2). This general prediction applies equally to men and women. Though the number of incident cases among men is predicted to remain higher, the rate of increase for both and men and women will be similar as the prediction lines move upward almost parallel to each other. Similarly, oral cancer-related mortality is also predicted to rise over the years for men and women in the EM region (Fig. 3). Again, the rate of rise is predicted to be similar between men and women even though mortality of men due to oral cancer is expected to remain higher. These figures are based on the number of cases and are not ratios against population denominator. The 

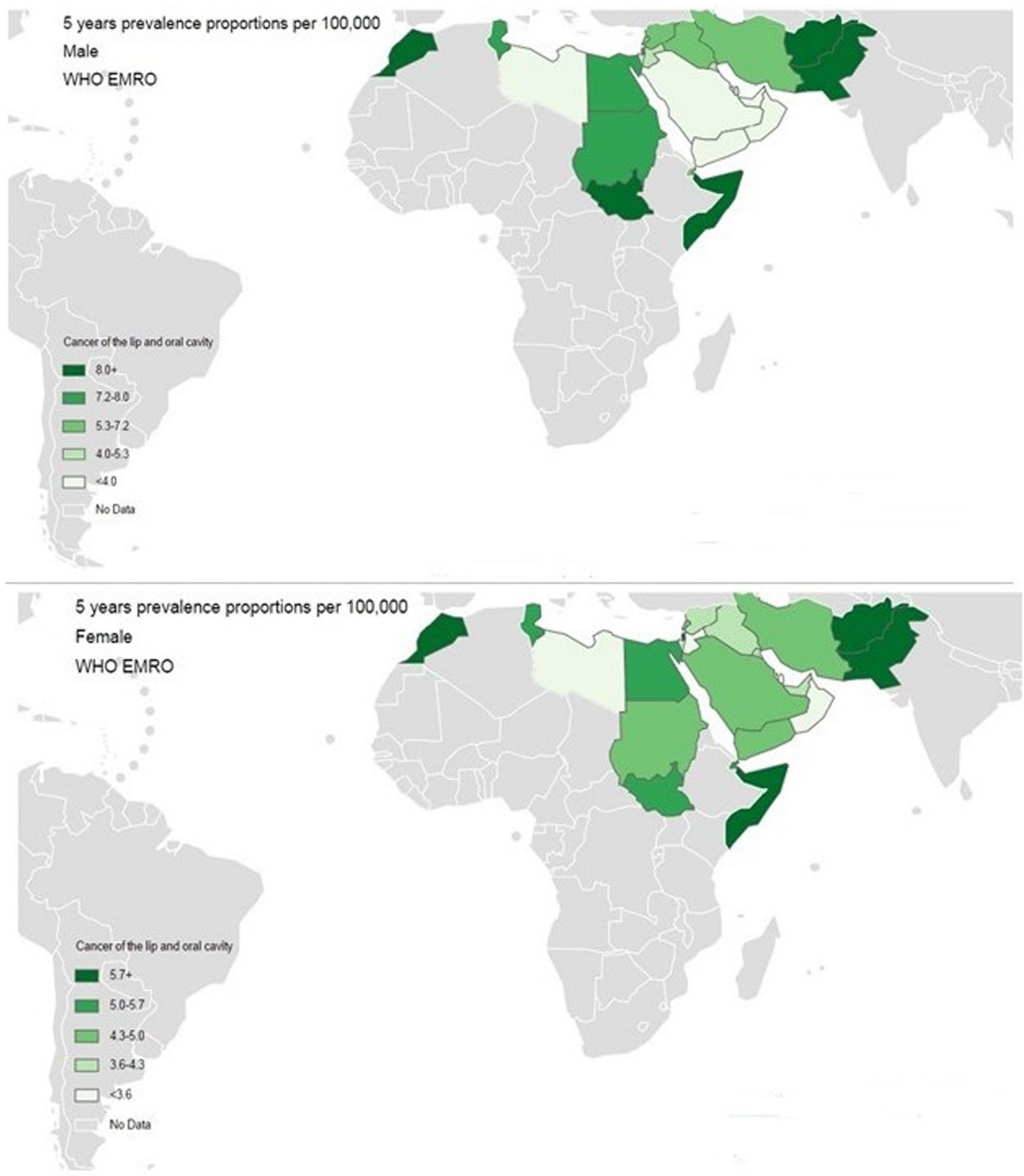

Fig. 1 Five-year prevalence proportion (per 100,000 population at risk) of lip and oral cancer in the Eastern Mediterranean region in men and women. Note the difference in scales between men and women before visual comparison by colors. Source: Globocan data, IARC

advantage of trying to assess the number of cases is that it provides the estimate of how many and how much resources the region will require to address the rapidly increasing burden of oral cancer. More cases mean more services and facilities to treat the cases, and it also implies greater emphasis on preventive 
Table 3 Estimated mortality: lip, oral cavity for EM region

\begin{tabular}{|c|c|c|c|c|c|c|c|c|c|}
\hline \multirow[t]{2}{*}{ Region } & \multicolumn{3}{|c|}{ All ages: both sexes } & \multicolumn{3}{|c|}{ All ages: male } & \multicolumn{3}{|c|}{ All ages: female } \\
\hline & Crude rate & ASR & Cumulative risk & Crude rate & ASR & Cumulative risk & Crude rate & ASR & Cumulative risk \\
\hline World & 2.1 & 1.9 & 0.22 & 2.8 & 2.7 & 0.31 & 1.4 & 1.2 & 0.13 \\
\hline EM region & 1.8 & 2.5 & 0.30 & 1.9 & 2.8 & 0.33 & 1.6 & 2.2 & 0.27 \\
\hline Afghanistan & 2.3 & 5.1 & 0.60 & 2.6 & 5.8 & 0.68 & 2.0 & 4.3 & 0.52 \\
\hline Bahrain & 0.3 & 0.4 & 0.05 & 0.4 & 0.5 & 0.06 & 0.2 & 0.2 & 0.03 \\
\hline Djibouti & 1.6 & 2.7 & 0.32 & 1.7 & 3.2 & 0.37 & 1.5 & 2.3 & 0.27 \\
\hline Egypt & 0.8 & 1.0 & 0.11 & 0.9 & 1.2 & 0.13 & 0.7 & 0.7 & 0.08 \\
\hline Iran, Islamic Republic of & 0.6 & 0.7 & 0.07 & 0.6 & 0.7 & 0.08 & 0.5 & 0.6 & 0.07 \\
\hline Iraq & 0.6 & 1.1 & 0.13 & 0.6 & 1.5 & 0.18 & 0.5 & 0.8 & 0.09 \\
\hline Jordan & 0.4 & 0.6 & 0.05 & 0.5 & 0.7 & 0.05 & 0.3 & 0.4 & 0.04 \\
\hline Kuwait & 0.3 & 0.4 & 0.05 & 0.2 & 0.3 & 0.03 & 0.3 & 0.7 & 0.08 \\
\hline Lebanon & 0.6 & 0.6 & 0.06 & 0.8 & 0.8 & 0.09 & 0.5 & 0.4 & 0.05 \\
\hline Libya & 0.2 & 0.3 & 0.04 & 0.2 & 0.3 & 0.04 & 0.2 & 0.3 & 0.04 \\
\hline Morocco & 1.0 & 1.2 & 0.14 & 1.2 & 1.4 & 0.18 & 0.9 & 0.9 & 0.10 \\
\hline Oman & 0.3 & 0.4 & 0.05 & 0.4 & 0.6 & 0.07 & 0.1 & 0.1 & 0.00 \\
\hline Pakistan & 4.0 & 5.9 & 0.70 & 4.4 & 6.3 & 0.73 & 3.6 & 5.4 & 0.66 \\
\hline Qatar & 0.3 & 0.4 & 0.04 & 0.3 & 0.5 & 0.06 & 0.0 & 0.0 & 0.00 \\
\hline Saudi Arabia & 0.3 & 0.6 & 0.07 & 0.3 & 0.6 & 0.07 & 0.3 & 0.6 & 0.07 \\
\hline Somalia & 1.1 & 2.3 & 0.27 & 1.1 & 2.4 & 0.29 & 1.1 & 2.1 & 0.26 \\
\hline South Sudan & 1.3 & 2.4 & 0.29 & 1.5 & 3.0 & 0.36 & 1.1 & 1.9 & 0.23 \\
\hline State of Palestine & 0.8 & 1.6 & 0.18 & 0.8 & 1.5 & 0.16 & 0.8 & 1.7 & 0.20 \\
\hline Sudan & 1.2 & 2.2 & 0.26 & 1.4 & 2.7 & 0.32 & 0.9 & 1.7 & 0.20 \\
\hline Syrian Arab Republic & 0.6 & 0.8 & 0.09 & 0.7 & 1.1 & 0.12 & 0.4 & 0.6 & 0.06 \\
\hline Tunisia & 0.7 & 0.7 & 0.08 & 0.9 & 0.9 & 0.10 & 0.6 & 0.5 & 0.06 \\
\hline United Arab Emirates & 0.2 & 0.5 & 0.06 & 0.2 & 0.5 & 0.07 & 0.2 & 0.5 & 0.05 \\
\hline Yemen & 0.7 & 1.5 & 0.17 & 0.6 & 1.3 & 0.16 & 0.8 & 1.6 & 0.17 \\
\hline
\end{tabular}

Rates are per 100,000 population at risk

EM region Eastern Mediterranean region, ASR age-standardized rate (against world standard population)

Data source: IARC, Globocan 2012

measures to keep disease burden minimized in the future. Although detailed country-wise figures are not presented here, general form of the predicted incident cases and associated mortality is similar for most countries.

\section{Data Limitations}

There exist several limitations to the data used for this analysis. Some data are estimates. For example, the "mortality data presented in Globocan 2012 are estimates based on recorded data available through the WHO mortality data bank for earlier periods together with prediction methods. In addition, the WHO mortality data may have been corrected to take into account some degree of incompleteness or under-coverage" $[5,6]$. Furthermore, the estimates are based on available information from various countries.
The population for the region may include some small country populations for which no estimates are provided which can introduce errors in accurately estimating population rates, incident cases, mortality, or prevalence of a disease. First, data for different countries and outcomes come from different years (range 2010-2013) though the range is narrow permitting some confidence in comparing them with respect to their timing. Data may be missing from some countries. Yet again, the quality and source of data from different countries is variable - some come from periodic surveys and some from sentinel data collecting events. Many of these may not necessarily be backed by rigorous standards that may be expected from cancer registries. Most countries do not have cancer registries. Yet, these are the only available data from the region, and decision making has to proceed with what is available. 
Fig. 2 Predicted number of new lip and oral cancer cases in EM region showing steady increase in numbers till 2035 both in men and women. Source: Globocan data, IARC

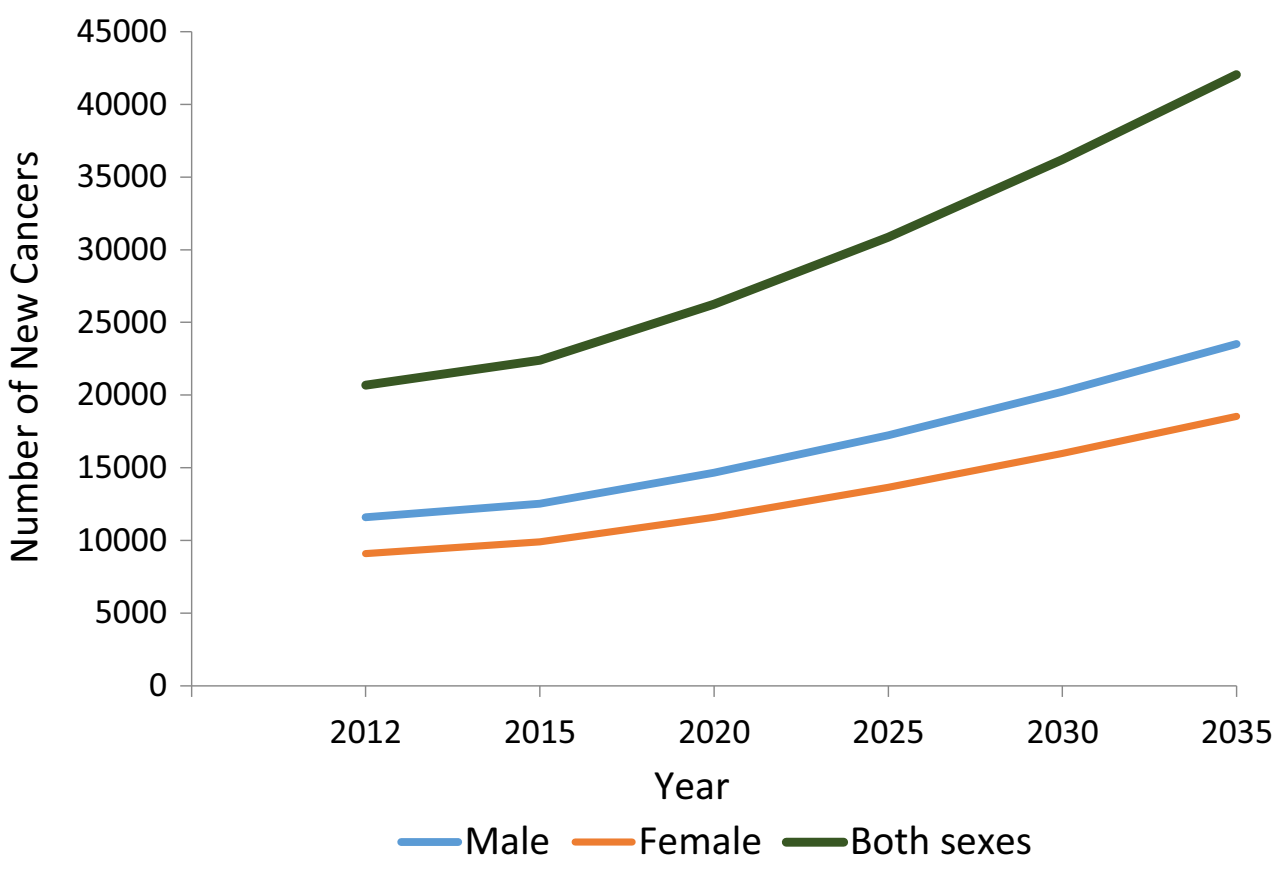

Globocan data are continuously improving in quality and extent. The estimates may not be truly comparable over time due to these changes in data quality and sources. Comparison of current estimates over time to older estimates published earlier requires careful understanding of the differences in data over time. It has been suggested that any observed differences may be the result of a change in the methodology and should not be interpreted as a time trend. A key factor that will improve reliability of studies and confidence in data is the establishment of cancer registries in every country permitting good tracking and surveillance for all cancer in the region.

Despite data uncertainties and some concerns about data quality from different countries, unless a differential bias is demonstrated towards over-counting cases, it is likely that the data error may actually under-count cases and therefore, its associated mortality. Furthermore, as political strife reduces, political powers should focus on robust data collection and setting up institutions to organize such efforts across the regions. Such efforts will perhaps find more cases and allow the
Fig. 3 Predicted number of deaths due to lip and oral cancer cases in EM region showing steady increase in numbers till 2035 both in men and women. Source: Globocan data, IARC

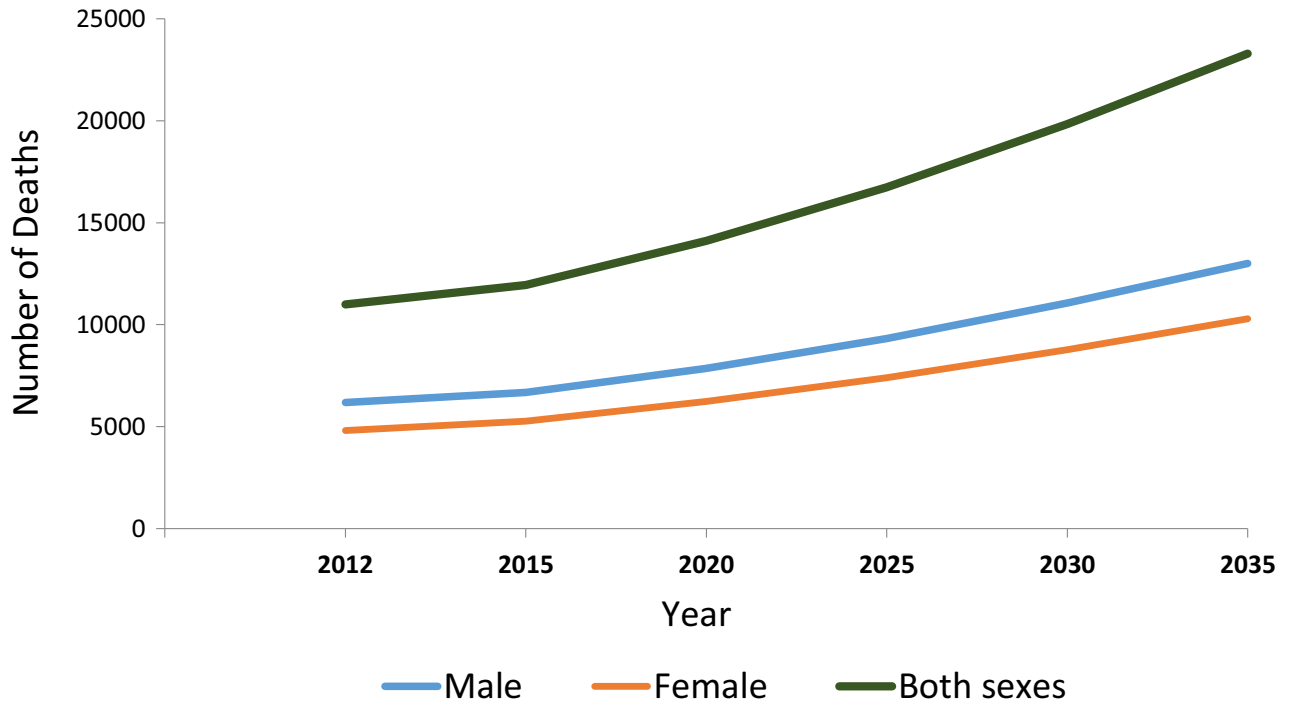


populations to become stabilized and leading a normal social life (for example a reduction in mass migration and resultant refugee problems). It is expected that the full effect of oral cancer-related risk factors in the EM region will become clearer, though differences between nations may not only be wide now, they may widen in the future as function of their economies. If this premise holds, then the actual burden of oral cancers in the EM regions is expected to be much higher than those available from Globocan data presented above.

\section{Conclusions}

The EM region represents a wide variability between countries related to their political structure, stability, civic facilities, and population's health status. Data from WHO suggests that the region as a whole is poised for an increase in the number of new oral cancer cases and its associated mortality. Current data suggests that most of the oral cancer burden in this region is driven by high rates in Pakistan and Afghanistan, but as normalcy of life returns to countries in strife and their respective governments establish robust healthcare infrastructure, the true burden of oral cancer will be visible, which may be higher than that seen now. Even assuming current political scenarios, the number and proportion of new cases, prevalence, and mortality related to oral cancer in the EM region is expected to rise substantially over the next 20 years.

\section{Compliance with Ethics Guidelines}

Conflict of Interest None of the authors have any conflicts of interest to declare.

Human and Animal Rights and Informed Consent This article does not contain any studies with human or animal subjects performed by any of the authors.

\section{References}

Papers of particular interest, published recently, have been highlighted as:

- Of importance

1. WHO. About WHO. WWW page. URL: http://www.who.int/about/ en/. Last accessed 27 May 2015.

2. Chattopadhyay A. Oral health epidemiology; principles and practice. Sudbury, MA: Jones and Bartlett Publishers; 2010.

3. IARC, WHO. The Globocan project. WWW page. URL: http:// globocan.iarc.fr/Default.aspx. Last accessed 27 May 2015.

4. WHO. Strategy for cancer prevention and control in the Eastern Mediterranean Region-Technical paper 2009. WWW page. URL: http://applications.emro.who.int/docs/EM_RC56_4_en.pdf. Last accessed 27 May 2015. This article suggests prevention cancer prevention strategies for the countries in the EM region

5. IARC, WHO. Glossary of terms. WWW page. URL: http:// globocan.iarc.fr/Pages/glossary.aspx. Last accessed 27 May 2015.

6. IARC, WHO. Data sources and methods. WWW page. URL: http:// globocan.iarc.fr/Pages/DataSource_and_methods.aspx. Last accessed 27 May 2015. 